\title{
Geomagnetic field modulates artificial static magnetic field effect on arterial baroreflex and on microcirculation
}

\author{
Juraj Gmitrov
}

Published online: 16 November 2006

(C) ISB 2006

\section{Erratum to: Int J Biometeorol \\ DOI 10.1007/s00484-006-0056-5}

In the "Discussion" subsection: Possible implementation, second pharagraph, the word "variability" is missing. The sentence should read: GMF activity was found earlier to decrease heart rate variability in adults (Otsuka et al. 2000; Cornélissen et al. 2002).

The online version of the original article can be found at http://dx.doi.org/10.1007/s00484-006-0056-5

\footnotetext{
J. Gmitrov

Department of Environmental Health,

National Institute of Public Health,

Tokyo 108, Japan

J. Gmitrov

Pro Vitac Hospital,

Gelnica 056 01, Slovak Republic

J. Gmitrov $(\bowtie)$

Visnova 6,

Presov 080 01, Slovak Republic

e-mail: gmitrovj@yahoo.com
} 